\title{
Towards a Self-Service Approach in the Printing \\ Industry. An Investigation of State of the Art \\ Technologies Along with Industry 4.0 Changes
}

sciendo

doi:10.2478/mape-2021-0021

Date of submission to the Editor: 05/2021

Date of acceptance by the Editor: 06/2021

MAPE 2021, volume 4, issue 1, pp. 232-244

\section{Wiesław Urban}

ORCID ID: 0000-0002-8240-381X

Bialystok University of Technology, Poland

Krzysztof Łukaszewicz

ORCID ID: 0000-0003-4323-7190

Bialystok University of Technology, Poland

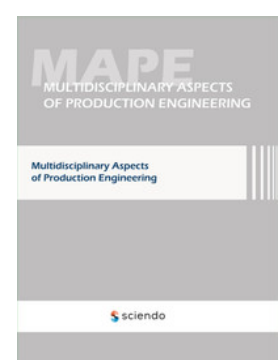

\section{INTRODUCTION}

The currently observed transformation of production is closely related to the introduction of technologies and solutions that are part of the Industry 4.0 concept (Wang et al., 2017). It can be observed that the ongoing technological changes in production are accompanied by a gradual evolution of consumption patterns. This results in the coexistence of different production paradigms. A trend toward the reorientation of enterprises towards the so-called mass personalisation of production is noticeable (Dou et al., 2020). The mass customisation of products is a manifestation of the implementation of the "Long Tail" strategy. This strategy is proving to be so effective that it is being incorporated into business strategies by more and more companies. Anderson (2008) posits that this strategy is the future of business, while Fischer et al. (2020) and Imgrund et al. (2017) highlight the importance of the improvement potential inherent in this strategy.

Industry 4.0 is often used as a collective term for different digital technologies (Szalavetz, 2019). Some researchers identify the digital transformation of manufacturing with manufacturing cyber-physical systems (CPS) (Chen, 2017; Monostori et al., 2016). It is widely believed that CPS represent a highly advanced stage of gradual convergence between manufacturing technologies and information and communication technologies (Chen, 2017; Tao et al., 2017), enabling vertical and horizontal linkage (collaboration and information sharing) (Szalavetz, 2019).

In the conceptual area of Industry 4.0, a number of interconnected digital technologies are emerging, e.g. artificial intelligence, the Internet of Things (IoT), Big Data, Cloud Computing and Blockchain, changing the supply chain and remodelling industrial competition (Ardolino et al., 2018). Manufacturing companies are increasingly using digital technologies to create a digitisation strategy (Sklyar et al., 2019). Digitisation is increasingly becoming one of the most important strategies for companies to survive and even thrive in an 
increasingly competitive environment (Ferreira et al., 2019). Furthermore, an increasingly service-oriented economy is driving many manufacturers to adopt a strategy, called servitisation, which can be understood as the process of combining services with products to generate revenue streams from these services by creating new value for customers (Zhou et al., 2021). Digital technologies such as loT or data analytics are seen as enablers and drivers of servitisation (Baines et al., 2020; Kohtamäki et al., 2020; Mosh et al. 2021). Consequently, classic servitisation in combination with digital technologies is emerging as a new field of interest (Suppatvech et al., 2019) and is commonly referred to as digital servitisation (Vendrell-Herrero and Wilson, 2017). At the same time, one can see a strand of literature that explores the interaction between servitisation and digitisation (Baines et al., 2017). One group of studies has highlighted the convergence of servitisation and digitisation, which is considered a single strategy (Coreynen et al., 2020; Gebauer et al., 2020). A second, different emerging group of studies considers servitisation and digitisation as two independent strategies (Mosh et al., 2021). Researchers in the second group examine the links between digitisation and servitisation without treating them as a whole strategy. For example, digitisation has been studied as a positive variable mediating the relationship between servitisation and firm performance (Martín-Peña et al., 2019). Adopting a strategy characterised by 'mass personalisation' and customisation of products requires greater emphasis on customer interaction and service. Customer expectations are shifting from buying/consuming products to adopting sophisticated solutions that solve contextual problems and create utility value. Instead of paying for products, business customers increasingly want to receive only the value inherent in product use, thus consuming it as a service (Cusumano et al., 2015; Gebauer et al., 2020). The 'product-as-a-service' model implies a change in approach not only to production, but also to the entire product design and life cycle. This is because it emphasises continuous interaction with the customer over a longer period, rather than a one-off sale and service during the warranty period.

The changes outlined also extend to the printing industry. It is possible to see an intensification of competition between strictly digital and traditional modes of content delivery, most often in the form of printed materials. This aspect was particularly highlighted by the COVID-19 pandemic. These constraints have contributed to modifying the strategies of many companies in the printing industry. Changes in technological and organisational solutions in the field of printing, which provide an opportunity for effective product personalisation, seem to be a very interesting issue for research.

The aim of the article is to analyse the state of the art technology in the field of medium and large-volume printing and then to identify challenges for further changes in the technology of printing of this type as well as technological and organisational changes in the processes of preparation and realisation of printing products. 
The article uses case studies of selected technologies offered by key technology suppliers in this area and case studies of selected business entities manufacturers of printing products. The research approach adopted in this article also takes conceptual work into account. The investigated area of technological and organisational changes fits into the current of changes called Industry 4.0.

\section{OFFSET TECHNOLOGIES FOR HIGH-VOLUME PRINTING}

In analogue printing techniques, the image carrier is the printing form. Khadzhynova and Jakucewicz (2016) state that classic printing techniques include relief printing (letterpress, flexography, letterset), offset, intaglio printing (rotogravure, intaglio, pad printing) and screen printing. Due to its great popularity and suitability for high-volume printing, this chapter focuses on offset printing.

Offset printing is characterised by the fact that the printing and non-printing elements are essentially in the same plane, and the image is transferred from the printing plate to the print via an additional element, an intermediate cylinder, which is covered with rubber. The printing form is mounted on a mould cylinder, which is in constant contact with the ink and dampening system. Since the printing areas of the mould are hydrophobic and the non-printing areas are hydrophilic, the mould accepts ink only in the hydrophobic areas that have not previously accepted the moistening solution. Table 1 presents the technological and design features of two selected models of sheetfed offset presses offered by HEIDELBERG and KOENIG \& BAUER (KBA). Following the assumptions of the case study method (Yin, 2018; Baxter and Jack, 2008), the most representative, in this case widely used in the sector, technological solutions were selected for analysis.

It should be emphasised that the Speedmaster XL 106 provides process support through the implementation of artificial intelligence (Al) solutions. It has a builtin function to preset print parameters and optimise sheet transport. The machine manufacturer also claims a plate changeover time of less than one minute with AutoPlate $X L$ 3. The Intellistart 3 software defines all the steps necessary for a job changeover completely without operator intervention, while Intelliguide simulates the time-optimised process sequence live and also prompts for manual steps. An interesting solution is the DriveTronic SPC used on the Rapida 106, which allows all forms of print to be changed simultaneously. At the highest level of automation, the machine can change jobs 'on the fly': (Flying Job Change) can be carried out practically without stopping the machine. The CleanTronic roller washing unit enables automatic roller washing with an optimised roller washing system and efficient collection of detergent from the ink rollers. 
Table 1 Selected technical parameters of offset printing machines

\begin{tabular}{|c|c|c|c|c|c|c|}
\hline Model & $\begin{array}{l}\text { Printing } \\
\text { rate }\end{array}$ & $\begin{array}{l}\text { Printing } \\
\text { units }\end{array}$ & $\begin{array}{l}\text { Maximum } \\
\text { sheet size }\end{array}$ & Thickness & Substrates & $\begin{array}{c}\text { Dimensions: } \\
\text { base } \\
\text { configuration } \\
\text { L x W x H }\end{array}$ \\
\hline - & $\begin{array}{c}\text { [sheets } \\
\text { per hour] }\end{array}$ & & {$[\mathrm{mm}]$} & {$[\mathrm{mm}]$} & - & {$[\mathrm{mm}]$} \\
\hline 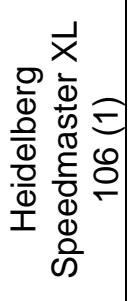 & $\begin{array}{l}\text { ○ } \\
\text { ○ } \\
\infty \\
\end{array}$ & 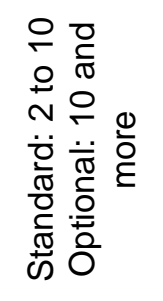 & 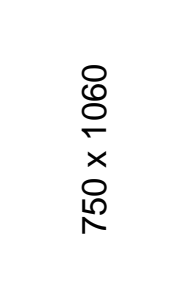 & $\begin{array}{l}\overline{0} \\
\stackrel{0}{0} \\
0 \\
0\end{array}$ & 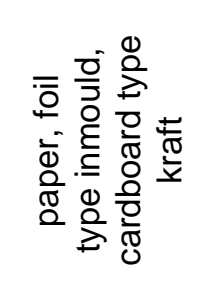 & 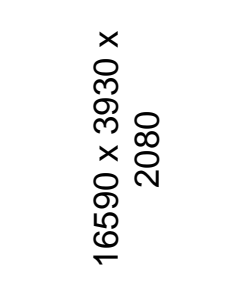 \\
\hline 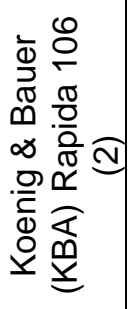 & $\begin{array}{l}\text { ঃ } \\
\text { ઠ }\end{array}$ & $\begin{array}{l}\stackrel{\text { N }}{0} \\
\stackrel{2}{O} \\
\stackrel{2}{J}\end{array}$ & 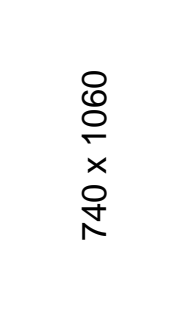 & $\begin{array}{l}\dot{\sigma}_{-} \\
\stackrel{0}{\circ} \\
\dot{0} \\
\dot{0}\end{array}$ & 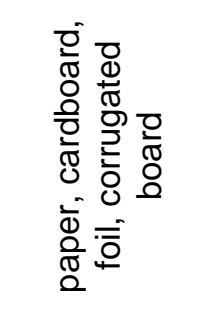 & 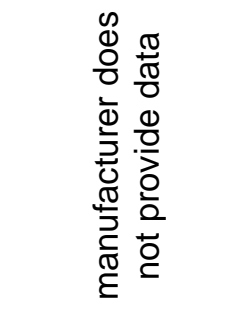 \\
\hline
\end{tabular}

Source: Own study based on: (1) - https://www.heidelberg.com/global/en/products/offset_ printing/format_70_x_100/speedmaster_xl_106/technical_data_equipment_10, (2) https://www.koenig-bauer.com/en/products/sheetfed/sheetfed-offset/medium-format/rapida$106 /$

\section{STATE OF THE ART TECHNOLOGIES IN DIGITAL PRINTING}

In digital printing techniques, the image carrier is the digital file. Kipphan (2001) provides a general division of digital printing methods, namely electrophotography, ionography, magnetography, spray printing, thermography and photography. Due to its mature technology and popularity, this paper focuses on the electrophotography method.

In digital processes, the photoconductive layer is exposed pixel by pixel using, for example, a laser beam. The digital electrophotographic printing process consists of several consecutive steps: loading of the photo-conductive layer, exposure of the image, development, transfer of toner to the printed substrate, and fixation of the print. The permanent print is obtained at the fixing stage due to the action of heat. Most electrophotographic machines use the method of toner fusing by heat and pressure.

There are many models of digital electrophotographic machines on the market today. These machines differ in the way the latent image is obtained, the development process and the transfer of the image to the substrate. There are also differences in the designs of the main units of these machines. Table 2 presents the technological and design features of two selected contemporary models of multicolour machines offered by XEROX and HP INDIGO.

On XEROX machines, the multi-colour image is collected by an intermediate transfer belt and this image is transferred to the substrate in a single pass. A different solution is found on HP INDIGO machines, which are built on the basis 
of one imaging section (one cylinder with a photoconductive layer and one image exposure head) and seven developing sections. The unquestionable advantage of HP INDIGO machines seems to be their high print quality, comparable to that of offset machines. An interesting feature of HP INDIGO machines is the Enhanced Productivity Mode (EPM) printing option - enabling CMYK printing in CMY mode. According to the manufacturer, this does not impair print quality, and because multicolour printing on the machine is carried out on the basis of a single printing section (one cylinder with a photoconductive layer), which significantly increases the printing speed.

Table 2 Selected technical parameters of electrophotographic machines

\begin{tabular}{|c|c|c|c|c|c|c|}
\hline Model & $\begin{array}{l}\text { Printing } \\
\text { rate }\end{array}$ & Resolution & $\begin{array}{l}\text { Maximum } \\
\text { sheet size }\end{array}$ & $\begin{array}{c}\text { Substrate } \\
\text { weight }\end{array}$ & Substrates & $\begin{array}{c}\text { Dimensions: } \\
\text { base } \\
\text { configuration } \\
\text { L x W x H }\end{array}$ \\
\hline- & $\begin{array}{l}\text { [sheets } \\
\text { per hour] }\end{array}$ & [dpi] & {$[\mathrm{mm}]$} & {$\left[\mathrm{g} / \mathrm{m}^{2}\right]$} & - & {$[\mathrm{mm}]$} \\
\hline 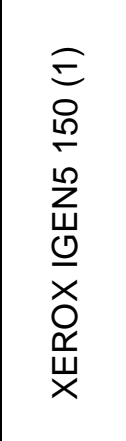 & ৪ి & 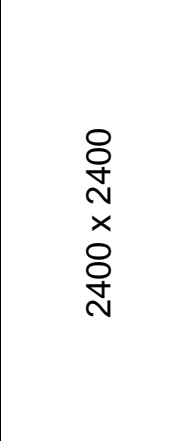 & 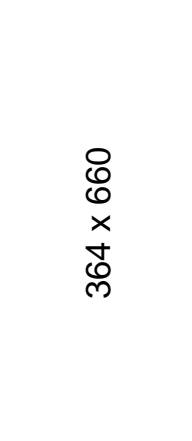 & $\begin{array}{l}\circ \\
\text { 이 } \\
+0 \\
\circ \\
0\end{array}$ & 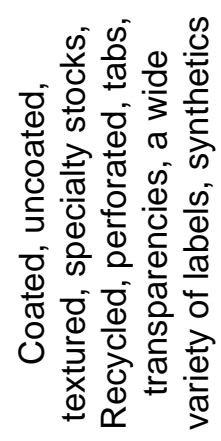 & 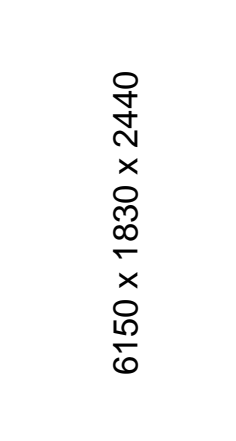 \\
\hline 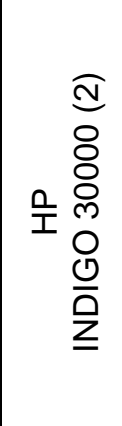 & 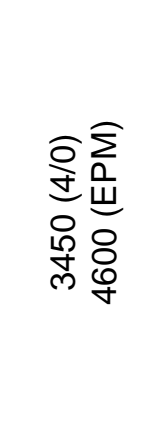 & 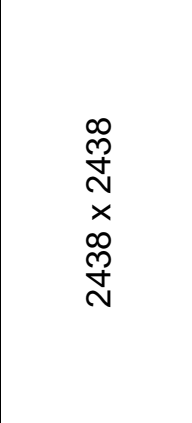 & 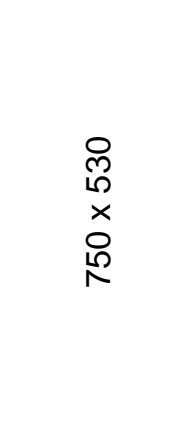 & 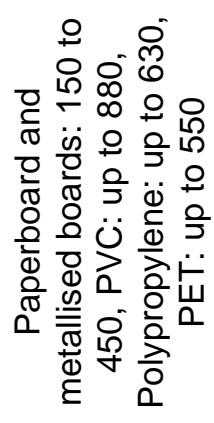 & 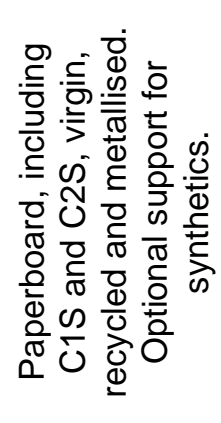 & 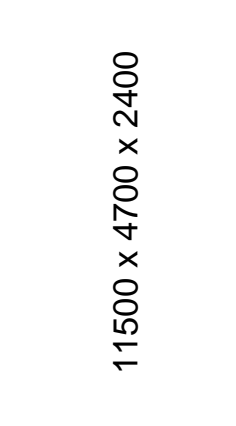 \\
\hline
\end{tabular}

Source: Own study based on: (1)-https://www.xerox.ca/en-ca/digital-printing/digitalpresses/xerox-igen5, (2)-https://www.hp.com/pl-pl/commercial-printers/indigopresses/30000.html

\section{PRODUCT PROCESS IN OFFSET PRINTING}

To determine how the product preparation process functions under the conditions of currently typical offset printing presses, a case study research study was conducted. A qualitative case study is a research approach that explores the phenomenon under investigation using multiple data and multiple sources (Baxter and Jack, 2008). The authors emphasise the crucial importance of defining the investigative purpose that the researchers set for the study and clearly establishing the boundaries for conducting the research (Baxter and Jack, 2008, Yin, 2018). An SME company operating in the premium carton 
packaging market was selected for the study, and in the next section of the article, a facility operating on a similar scale but operating in digital printing technology. In both cases, the aim was to identify the course of the process of creating a printing product from the first contact with the customer to the dispatch of the finished product to the customer, paying attention to issues related to the technologies used.

In the entity under analysis, several variants of the process of product preparation and realisation take place, the most complex and time-consuming of which is the variant including the complete design of the packaging for the customer. In the studied case, of 250 consecutive orders from the selected period, 40 were orders for completely new products, which constitutes 16\%, 110 were orders including changes to the product ordered, $44 \%$ of the analysed orders. The case of preparing a completely new product will be analysed later. The facility uses offset machines similar to those described above.

Preparation of an offer for a customer includes, apart from commercial matters, important elements from the point of view of preparing the production of a product. At the stage of preparation and acceptance of the offer, the use of appropriate materials, types of printing substrate and inks, layout in formats, and the technological specification of the printing process are determined. The development of a graphic design for packaging is another important task carried out by the printing company. Recipients, the producers of various types of products who order packaging, usually provide files with the graphic design of the packaging, but they require appropriate processing and the work of designers to bring them to a state that can be used in the printing process. A number of orders require packaging graphics to be designed for the customer according to instructions provided by the customer. The developed design is printed in appropriate quality and sent by courier service for customer approval. The detailed layout of the sheets is carried out using specialised software. Various technological variables are detailed, such as the number of passes through the printing machine, types of rollers, and others. Various materials and components are completed, including those for processes outside the printing process. Sheet metal for the printing machines and the polymers that will be installed on the machine for a given order are then made.

Starting a given job on a printing machine requires the machine to be set up, i.e. the preparation for the job is combined with activities related to the completion of the previous order that was run on the machine. As soon as the machine is ready for printing, the production job is started. In the case of some orders, usually from new and particularly demanding customers, the print is accepted by a representative from the customer who personally comes to the plant. Fig. 1 shows the process flow with the production realisation stage. The time taken for the whole process, from placing the order by the customer to sending them the finished product, is ten days. 


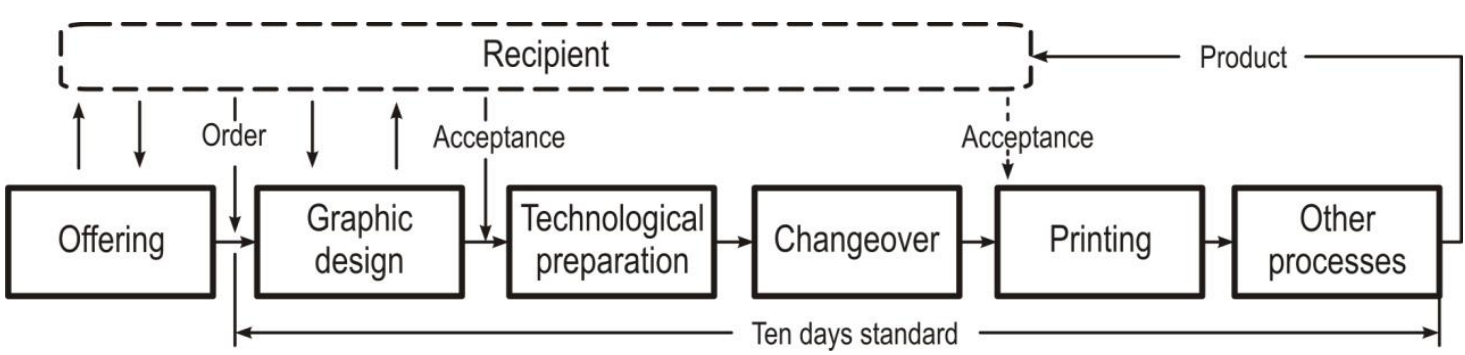

Fig. 1 Production preparation and implementation process in offset technology

\section{PRODUCT PROCESS IN DIGITAL PRINTING}

Offset technology has an established place in the printing sector, but it is uncertain how long this will last. Digital technologies have been gaining ground for some time and are increasingly used for small and even medium print runs. In the Polish edition of the Yellow Pages, one of the largest databases of economic entities, in the middle of 2021 there were almost 1,400 entities registered in the country, which offer printing in digital technology. A detailed search of the database reveals that printing entities offering digital printing often also work with offset printing. Such entities have introduced digital printing technology as a complementary solution to offset printing, enabling the realisation of smaller production volumes. It can also be seen that digital printing is being carried out by companies whose activities have grown out of graphic design and advertising services.

The analysis of the process of preparation and realisation of the product was carried out in an entity that realises digital printing with full online order processing. Products offered in such a way are characterised by their standardisation, i.e. a customer visiting a printing house's Internet shop can choose from dozens of product variants, there are also detailed guides on how to prepare his product graphically, there are detailed technical guidelines for graphic files, there are mock-ups available for download and use. Therefore, the first step of the process is to choose the right printing product in the shop, after which it is necessary for customers themselves to prepare the graphics and layout of the product.

The customer then uploads his files and determines the detailed parameters of his product by selecting various variables from a menu. Having specified their requirements in this way, the customer proceeds to place the order and pay. After paying for the order, the prepared personnel of the printing house verify the correctness and quality of the graphic design presented and if the files provided by the customer ensure correct printing as specified in the order, the order is sent to the production queue. In the case of digital printing, there is no need. The lead time from placing the order to dispatching it to the customer is two days.

If the result of verification of the submitted graphic files is negative, i.e. the printing house specialist determines that it will not be possible to achieve the expected product quality parameters on the basis of them, this information is sent to the ordering party. Along with this, they are presented with an offer of 
changes in graphic files by the company along with the time limit in which the specified changes will be introduced. The studied entity, as well as the majority of entities in the country at the time of the research, provides a two-day or even shorter time of completion of the product using digital printing technology.

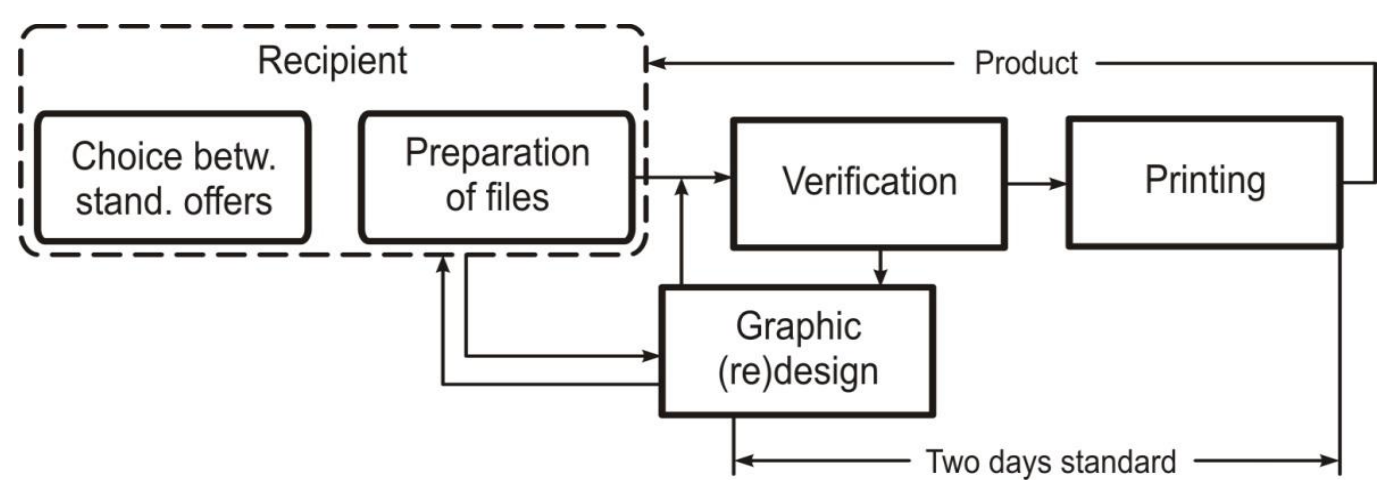

Fig. 2 Product preparation and realisation process in digital printing technology

Fig. 2 presents a schematic representation of the product preparation and realisation process in the case of printing in digital technology. It should be noted that this entity also carries out production in offset technologies, where with standardised products and fully online service it ensures lead times similar to those in digital technologies.

\section{DISCUSSION}

It can now be said that the quality of digital prints is equal to that of offset prints. The productivity of digital printing machines is also increasing and is approaching that of conventional machines. The use of digital printing techniques is growing and penetrating such industrial areas as packaging, decorative and functional printing. According to Khadzhynova and Jakucewicz (2016), the most important advantages of digital printing include the relatively low cost of a print proof, almost independent of the amount of print run, the ability to print variable data and to print low print runs along with the easy renewal of print runs without incurring large costs. Digital printing also reduces the use of chemicals and generates less waste (DPM, 2020), making its negative environmental impact much lower than analogue printing.

Digital packaging printing may be more expensive on a per unit basis, but it can also offer savings when considering the entire lifecycle of the packaging (Time, 2017). In this regard, manufacturers can accept a higher packaging cost if it translates into a faster time to market, which undoubtedly represents a business advantage. According to the forecast (Smithers, 2019), digital printing will grow as it allows cost-effective production of a greater variety of prints tailored to the recipient, and in essence, the content of these can be tailored much closer to the end user. Furthermore, the share of digital printing in the overall market is increasing in value terms from 17.4\% in 2019 to a projected $202421.1 \%$ (Smithers, 2019). Data from the report (FESPA, 2018) suggests that print as a customer-centric industry will be transformed as companies encounter a 
continuous trend towards mass personalisation. The report (FESPA, 2018) also found that $72 \%$ of users surveyed report an increasing demand for fast turnaround, $61 \%$ see increasing demand for short runs, and $59 \%$ see increasing expectations for on-time delivery.

The challenges faced by manufacturers of new device solutions are mainly due to the known disadvantages of digital printing (Khadzhynova and Jakucewicz, 2016), which include lower resistance of the print to external factors, technological limitations in the selection of print material and a narrower spectrum of available materials.

Juxtaposing the two identified processes of preparing and producing a printed product, three observations should be considered key. Firstly, the process based on the digital printing technology and Internet customer service, which goes hand in hand with it, requires the customer to carry out the whole process of preparing the product on their own, the producer provides quite extensive information support and gives quantitative requirements as to particular parameters, but it is the customer who must carry out the whole preparation on their own, which in the traditional process based on offset printing is not an expected task. In the case of the digital printing process, there is also the possibility to carry out the product preparation, but this option is not shown at the level of the online shop in the facility surveyed.

A characteristic feature of the process based on digital printing and electronic handling is the high standardisation of products. In the traditional approach, technical details, and as is well known, a print product is characterised by a multitude of possible variants, are specified in individual discussions between the print provider's sales consultant and the customer. Standardisation, i.e. the detailed specification of product variants, allows detailed guidelines to be linked to them for the preparation of the product for customers and, at the same time, facilitates the rapid start-up of the printing process, including material preparation.

The third key feature that differentiates the two processes is the turnaround times. There is a clear advantage of the digital process. At the same time, a detailed assessment of the course of processes, including the values of technological times in both variants/technologies, allows us to conclude that the large difference in lead times, amounting to as much as eight days between the two cases, has its source not in the technology of production of products itself, but in the organisation of the process of customer service and other organisational processes in both analysed entities. One of the factors enabling the digital process to meet the two-day lead time is the standardisation mentioned above.

One of the most important directions of changes in the customer service process, which will certainly be implemented in the near future by entities operating in a similar way as the second of the studied cases, is the use of tools based on Al, which will provide support to customers in the self-preparation of products, allowing, among other things, intelligent prompts and their own 
"machine" proposals for the design of printing products. Al solutions will make it possible to learn from the experiences of individual orders and then to intelligently guide customers through the preparation process and assist them with or relieve them from many detailed tasks.

\section{CONCLUSIONS}

In the case study part of the organisation, a case operating in the traditional formula and a case that uses not only digital printing technologies but also online customer service were deliberately selected. The directions of technological change indicate that the second case study sets the direction of upcoming changes in this sector of the economy.

Online service, the successive application of Al and Big Data are very likely to change the way customers are served and the production processes themselves in the printing sector. It will be important for manufacturers of digital printing equipment to overcome further challenges, such as increasing the range of printable substrates. The challenge of increasing the range of substrates is quite apparent in electrophotographic printing. The problem is the specific process of transferring the toner image to the substrate and the fusing processes, which impose limitations on the substrates used. In light of this analysis, liquid toner technology and digital spray printing seem promising.

Digital printing makes it possible to carry out a print order in a very short time, in fact immediately after receiving an order. It should be emphasised that this fits in perfectly with the trend towards mass personalisation of products, especially with the use of web-based print-on-demand solutions. In turn, business customers can take advantage of personalisation and the print-on-demand model when ordering, for example, business cards and high-quality marketing materials. Research shows that this type of technology will dominate the printing sector in the near future as the cost of digital printing decreases in medium and large runs.

\section{ACKNOWLEDGEMENTS}

This research was funded by a grant from the Minister of Science and Higher Education received by the Bialystok University of Technology, grant number WZ/WIZ-INZ/3/2019.

\section{REFERENCES}

Anderson, C. (2006). The Long Tail: Why the Future of Business is Selling Less of More. Hyperion, New York.

Ardolino, M., Rapaccini, M., Saccani, N., Gaiardelli, P., Crespi, G., Ruggeri, C. (2018). The Role Of Digital Technologies for the Service Transformation of Industrial Companies. International Journal of Production Research, 56(6), pp. 2116-2132, DOI: 10.1080/00207543.2017.1324224.

Baines, T., Bigdeli, A.Z., Sousa, R., Schroeder, A. (2020). Framing The Servitization Transformation Process: A Model To Understand and Facilitate The Servitization Journey. International Journal of Production Economics, 221, 107463, https://doi.org/10.1016/j.ijpe.2019.07.036. 
Baines, T., Ziaee Bigdeli, A., Bustinza, O.F., Shi, V.G., Baldwin, J., Ridgway, K. (2017). Servitization: Revisiting The State-Of-The-Art and Research Priorities. International Journal of Operations \& Production Management, 37(2), pp. 256278. https://doi.org/10.1108/IJOPM-06-2015-0312.

Baxter P. and Jack S. (2008). Qualitative Case Study Methodology: Study Design and Implementation for Novice Researchers. The Qualitative Report, 13(4), pp. 544559.

Chen, H. (2017). Theoretical Foundations for Cyber-Physical Systems: A Literature Review. Journal of Industrial Integration and Management, 2(3), 1750013, https://doi.org/10.1142/S2424862217500130.

Coreynen, W., Matthyssens, P., Vanderstraeten, J., van Witteloostuijn, A. (2020). Unravelling the Internal and External Drivers of Digital Servitization: A Dynamic Capabilities and Contingency Perspective on Firm Strategy. Industrial Marketing $\begin{array}{lll}\text { Management, 89, 265-277, } & \text { 8p. }\end{array}$ https://doi.org/10.1016/j.indmarman.2020.02.014.

Cusumano, M.A., Kahl, S.J., Suarez, F.F. (2015). Services, Industry Evolution, and the Competitive Strategies of Product Firms. Strategic Management Journal, 36(4), 559-575, https://doi.org/10.1002/smj.2235.

Dou, R., Huang, R., Nan, G., Liu, J. (2020). Less Diversity But Higher Satisfaction: An Intelligent Product Configuration Method for Type-Decreased Mass Customization. Computers \& Industrial Engineering, 142, 106336, https://doi.org/10.1016/j.cie.2020.106336.

DPM, (2020). Digital Printing Market - Growth, Trends, Forecasts (2020 - 2025). https://www.reportlinker.com/p05999335/Digital-Printing-Market-Growth-TrendsForecasts.html?utm_source=GNW [Accessed 15 Jun. 2021].

Ferreira, J.J., Fernandes, C.I., Ferreira, F.A., 2019. To Be Or Not To Be Digital, That Is the Question: Firm Innovation and Performance. Journal of Business Research, 101, 583-590, https://doi.org/10.1016/j.jbusres.2018.11.013.

FESPA, (2018). 2018 Print Census Reveals Strategic Responses to Escalating Demand. FESPA Staff. https://www.fespa.com/en/news-media/pressreleases/2018-print-census-reveals-strategic-responses-to-escalating-demand [Accessed 11 Jun. 2021].

Fischer, M., Imgrund, F., Janiesch, Ch. (2020). Prioritizing and Organizing the Modeling of the Long Tail of Business Processes, in Proceedings of the 28th European Conference on Information Systems (ECIS), An Online AIS Conference, June 1517, 2020, https://aisel.aisnet.org/ecis2020_rp/18.

Gebauer, H., Paiola, M., Saccani, N., Rapaccini, M. (2021). Digital Servitization: Crossing the Perspectives of Digitization and Servitization. Industrial Marketing Management, Vol. 93, pp. 382-388, https://doi.org/10.1016/ j.indmarman.2020.05.011.

Imgrund, F., Fischer, M., Janiesch, Ch., Winkelmann, A. (2017). Managing The Long Tail of Business Processes, in Proceedings of the 25th European Conference on Information Systems (ECIS), Guimarães, Portugal, June 5-10, 2017, https://aisel.aisnet.org/ecis2017_rp/39.

Khadzhynova S. and Jakucewicz S. (2016). Digital Printing Methods (in Polish). Lodz University of Technology Press, Lodz.

Kipphan H. (2001). Handbuch der Printmedien. Springer-Verlag, Berlin, Heidelberg.

Kohtamäki, M., Parida, V., Patel, P.C., \& Gebauer, H. (2020). The Relationship Between Digitalization and Servitization: The Role of Servitization in Capturing the Financial Potential of Digitalization. Technological Forecasting and Social Change, 151, 119804, https://doi.org/10.1016/j.techfore.2019.119804.

Martín-Peña, M. L., Sánchez-López, J. M., Díaz-Garrido, E. (2019). Servitization And Digitalization in Manufacturing: The Influence on Firm Performance. Journal of Business \& Industrial Marketing, 35(3), pp. 564-574. https://doi.org/10.1108/JBIM-12-2018-0400. 
Monostori, L., Kádár, B., Bauernhansl, T., Kondoh, S., Kumara, S., Reinhart, G., Sauer, O., Schuh, H., Sinn, W., Ueda, K. (2016). Cyber-Physical Systems in Manufacturing. CIRP Annals, 65(2), pp. 621-641, https://doi.org/10.1016/j.cirp.2016.06.005.

Mosch, P., Schweikl, S., Obermaier, R. (2021). Trapped In the Supply Chain? Digital Servitization Strategies and Power Relations In The Case Of An Industrial Technology Supplier. International Journal of Production Economics, 236, 108141, https://doi.org/10.1016/j.ijpe.2021.108141.

Sklyar, A., Kowalkowski, C., Tronvoll, B., \& Sörhammar, D. 2019. Organizing For Digital Servitization: A Service Ecosystem Perspective. Journal of Business Research, 104, pp. 450-460, https://doi.org/10.1016/j.jbusres.2019.02.012.

Smithers, (2019). Digital Print Increases Market Share to 21.1\% Displacing Analogue Print Market. https://www.smithers.com/resources/2019/jun/digital-printincreases-market-share [Accessed 10 Jun. 2021].

Suppatvech, Ch., Godsell, J., Day, S. (2019). The Roles of Internet of Things Technology In Enabling Servitized Business Models: A Systematic Literature Review. Industrial Marketing Management, 82, pp. 70-86, https://doi.org/10.1016/j.indmarman.2019.02.016.

Szalavetz, A. (2019). Industry 4.0 and Capability Development in Manufacturing Subsidiaries. Technological Forecasting and Social Change, 145, pp. 384-395, https://doi.org/10.1016/j.techfore.2018.06.027.

Tao, F., Cheng, Y., Zhang, L., Nee, A.Y.C. (2017). Advanced Manufacturing Systems: Socialization Characteristics and Trends. Journal of Intelligent Manufacturing, 28, pp. 1079-1094, https://doi.org/10.1007/s10845-015-1042-8.

Time, (2017). Time to Transform. Understanding the Digital Package Printing Landscape. https://www8.hp.com/h20195/v2/GetPDF.aspx/4AA7-4151ENW.pdf [Accessed 15 Jun. 2021].

Vendrell-Herrero, F. and Wilson, J.R. (2017). Servitization for Territorial Competitiveness: Taxonomy and Research Agenda. Competitiveness Review, 27(1), pp. 2-11. https://doi.org/10.1108/CR-02-2016-0005.

Wang, Y., Ma, H-S., Yang, J-H., Wang, K-S. (2017). Industry 4.0: A Way From Mass Customization to Mass Personalization Production. Advances in Manufacturing, 5, pp. 311-320.

Yin, R.K. (2018). Case study research: Design and methods (6th ed.). Thousand Oaks, CA: Sage.

Zhou, D., Yan, T., Dai, W., Feng J. (2021). Disentangling the Interactions Within and Between Servitization and Digitalization Strategies: A Service-Dominant Logic. International Journal of Production Economics, 238, 108175, https://doi.org/10.1016/j.ijpe.2021.108175. 
Abstract: It is commonly believed that the current economic state of many countries is at the stage of the fourth industrial revolution. The changes resulting from this revolution are affecting all sectors of the economy, including the printing sector. The aim of this article is to analyse the state of the art technology in sheetfed printing and then to identify the challenges for further changes in the technology of this type of printing as well as technological and organisational changes in the processes of preparation and realisation of printing products. The article uses case studies of selected technologies offered by key technology suppliers in this area and case studies of selected business entities - manufacturers of printing products. The research approach adopted in this article also takes conceptual work into account. It was found that the observed changes in the printing industry are consistent with the assumptions of the Industry 4.0 concept in the aspect of the digitisation and mass personalisation of products, which leads to the thesis that in the future personalised digital printing ordered through self-service will play a dominant role.

Keywords: Industry 4.0, servitization, mass-customization, printing industry 